\title{
Acquired Immune Deficiency Syndrome in Man and Animals-A Review
}

\author{
Maduike C. O. Ezeibe*, Ijeoma J. Ogbonna \\ Department of Veterinary Medicine, Michael Okpara University of Agriculture, Umudike, Nigeria \\ Email: mijejoy@yahoo.com
}

Received 23 February 2015; accepted 24 March 2015; published 26 March 2015

Copyright (C) 2015 by authors and Scientific Research Publishing Inc.

This work is licensed under the Creative Commons Attribution International License (CC BY). http://creativecommons.org/licenses/by/4.0/

c) (i) Open Access

\begin{abstract}
The paper defined acquired immune deficiency syndrome (AIDS) as a hematological abnormality rather than a clinical abnormality. Viruses that cause AIDS in man and animals are reviewed. Suggestion that human immune deficiency virus (HIV) which causes HIV/AIDS in man is a mutant of simian immune deficiency virus (SIV) which causes SIV/AIDS in nonhuman primates is also reviewed. For a simple test to enable researchers in the developing countries which have the highest incidences of HIV/AIDS, join the global search for more effective treatment for the pandemic, direct passive hemagglutination test has been developed for in vitro testing of drugs, herbs and minerals that may have antiretroviral effects. Also reviewed are the similarities in pathogenesis of HIV infection in man and pathogenesis of infectious bursa disease virus (IBDV) in chicks to assess possibility of developing vaccine for HIV/AIDS. Finally, antiretroviral effects of medicinal synthetic aluminum-magnesium silicate as cure for HIV/AIDS were reviewed.
\end{abstract}

\section{Keywords}

HIV, In Vitro Test, Prospect of Vaccine, A Potential Cure

Immune deficiency syndrome is a hematological abnormality defined by low blood lymphocytes counts [1]. Lymphocytes are responsible for immune response of animals to infections. So, when they are significantly fewer than normal, the animal or human-being will not be able to mount enough immune response against infections. Immune deficiency syndrome is therefore not a clinical abnormality. Most of the observable clinical signs associated with the syndrome are those of secondary infections. For that reason, some persons or animals can be immune deficient without manifesting observable signs of disease.

Some animals or human-beings can have low blood lymphocytes counts from birth, as a genetic defect but

*Corresponding author.

How to cite this paper: Ezeibe, M.C.O. and Ogbonna, I.J. (2015) Acquired Immune Deficiency Syndrome in Man and Animals-A Review. World Journal of AIDS, 5, 50-57. http://dx.doi.org/10.4236/wja.2015.51006 
when a person or an animal that was born with normal blood lymphocytes counts develops significantly low blood lymphocytes counts, such immune deficiency is described as acquired. Most cases of acquired immune deficiency in man and animals occur as a result of viral infections. Some viruses have affinity for the lymphocytes and so destroy them. When the lymphocytes become too few to produce enough immunity, such individuals succumb to any infection that comes their way. In other words, clinical manifestations of immune deficiency syndromes, whether they are genetic or acquired, vary depending on secondary infections in the patient's environment.

Acquired immune deficiency syndrome (HIV/AIDS) is therefore qualified to be called infectious immune deficiency syndrome or viral immune deficiency syndrome. Most cases of AIDS in man and in other mammals are caused by Lentiviruses [2], a genus of single stranded RNA viruses of the family Retroviridae while in chicks a similar hematological abnormality is caused by another RNA virus called infectious bursa disease virus (IBDV), a Birnaviridae virus [3]. The Lentivirus that causes AIDS in humans is called Human immune deficiency virus (HIV). The cause in the nonhuman primates is simian immune deficiency virus (SIV). Lentiviruses that cause slowly progressive immune deficiency have also been isolated from horses, cattle, sheep and cats [1].

There are different theories about how HIV became a human pathogen. The best accepted theory is that SIV of the nonhuman primates mutated to HIV and became adapted to human cells. The first suspicion that HIV-1 originated from primates arose when a wild chimpanzee from Gabon was found to harbor a lentivirus that was isogenic to HIV-1 [1]. That is, the "SIV" genome carried the same nine reading frames as HIV-1, including an accessory gene termed $v p u$, which had before then been identified only in HIV-1. Also, in 1999, researchers confirmed that tissues from a chimpanzee contained a form of SIV that was identical to HIV-1. This therefore suggested that HIV-1 originated from the nonhuman primates [1].

What the viruses cause in their respective hosts is the hematological abnormality which predisposes infected animals to secondary infections. So, actual clinical signs manifested depend on the secondary infections each patient is exposed to. For that reason, clinical manifestations of AIDS are so varied that it may be better described as a multi-systemic disease. What justifies tentative diagnosis of AIDS is deficiency in number of blood lymphocytes, established by total and differential leucocytes counts.

Clinical signs so far associated with HIV/AIDS in man include anxiety, dementia, depression, insomnia, emaciation, dermatitis, bouts of fever, pneumonia and multiple boils [1]. Some patients complain of joint pains. In Nigeria, some HIV/AIDS patients come down with tuberculosis or viral hepatitis as secondary infections. CD4-T lymphocytes counts of less than 200 cells per ml of blood, compared to about 1000 CD4-T lymphocytes per $\mathrm{ml}$ for healthy people, justify tentative diagnosis of HIV/AIDS even if clinical signs are not yet evident in the individual.

Detection of HIV antibodies in plasma of suspected cases, by serological tests, is most common method of confirming diagnosis of HIV/AIDS. Antibodies to HIV infection take from six weeks to six months to appear in blood of infected individuals. So, the tests should be repeated in individuals who consistently have low CD4-T lymphocytes counts but test negative for HIV antibodies. Consecutive negatives for HIV antibodies to tests done over a period of at least six months are required before a patient with persistent significantly low CD4-T lymphocytes counts can be declared HIV negative [1].

Tests commonly used for diagnosis of HIV/AIDS include-enzyme-linked immunosorbent assay (ELISA): If a person is HIV positive by ELISA test, then Western blot test is done to confirm the diagnosis.

Home Tests: The only home test approved by the Food and Drug Administration of United States of America is called the Home Access Express Test, which is sold in pharmacies.

Saliva Tests: A cotton pad is used to obtain saliva from inside cheek of the individual. The pad is then placed in a vial and submitted to a laboratory for testing. Results are got in three days. Positive results should be confirmed with a blood test [1].

Viral Load Test: This test estimates amount of HIV in blood by enumerating copies of RNA per ml of plasma. Viral load test is the test generally used to monitor outcome of treatment. In healthy persons, copies of RNA per $\mathrm{ml}$ of blood should not exceed 50. So, in patients who have already been confirmed positive for HIV infection, increase in number of copies of RNA in excess of $50 / \mathrm{ml}$ is used to estimate titer of HIV in the patients' blood.

There was a need for a simple, rapid and affordable in vitro test for HIV titer in specimens so that claims of antiretroviral effects of new medicines, herbs and minerals can be tested [4]. Those that give good results can then be used for clinical trials and outcome of the trials also scientific verified by testing plasma of treated patients for titer of the virus. Development of such test would enable scientists who work in laboratories that lack 
sophisticated equipment as is the case in many African countries where highest burden of HIV/AIDS pandemic occurs, to participate in the current global effort to search for more effective and affordable cure for it.

Passive hemagglutination (PHA) test, a laboratory test that is already in use for detection of HIV antibodies, was therefore modified to develop the direct passive hemagglutination (DPHA) test for assessment of titer of HIV antigen in plasma. DPHA test: Principle of passive hemagglutination test is that viruses adsorb to red blood cells of given animal species as first stage of infection of the cells. Before the viruses penetrate into the cells' cytoplasm, if contact with homologous antibodies is made, they also attach to the antibodies. The resultant antigen-antibody complexes prevent the RBCs from settling to discrete buttons in wells of microtiter plates, giving the impression of viral hemagglutination.

PHA test is usually performed by sensitizing RBCs of given animal species with a known virus, so that when the sensitized RBCs are reacted to dilutions of serum samples, if antibodies to the virus are present in the sera, passive agglutination of the RBCs occurs. So, the test is able to detect presence of viral antibodies. To apply principles of passive hemagglutination to develop a Modified passive hemagglutination (MPHA) test [5] for determination of titers of viruses, we sensitized RBCs of specific animal species with dilutions of specimens suspected to contain viruses known to infect the RBCs and reacted the sensitized RBCs onto sera containing known antibodies to the suspected viruses.

MPHA test is used to detect viruses from specimens that contain only the virus while the known antibodies are in sera. In the case of HIV infection, both the virus and its antibodies are found together in plasma and in other secretions and excretions of HIV/AIDS patients. So, the MPHA was further modified to develop the DPHA. The Direct passive haemagglutination test for HIV, took advantage of the fact that plasma of infected persons contain high concentrations of both the antibodies and the virus. So, all that is needed is to provide susceptible RBCs and environmental conditions necessary for viral adsorption to take place. At $37^{\circ} \mathrm{C}$ for 30 minutes, both adsorption of HIV onto sheep RBCs and HIV antigen-HIV antibody reaction take place to produce passive agglutination of the RBCs.

In the PHA test, for viral antibodies and in the MPHA test for viral antigens, the antigen or the positive serum (antibodies) to be used as reagent is known. So, a positive reaction identifies what is in the specimen being tested as homologous complement of the known antigen or of the known antibody. In the case of DPHA for HIV antigens, the antibodies have to be confirmed in the plasma by another test (ELISA) before testing for the virus, to serve as a proof that the passive agglutination of sheep RBCs is a result of reaction of HIV antigens with HIV antibodies.

Also, since both HIV antibodies and the antigen must be present for the passive agglutination to take place, end point for DPHA test could be as a result of exhaustion of either the antibody or the antigen. So, it is necessary to test the next higher dilution to titer of each plasma, for HIV antibodies, to ensure that the antibodies remain so that it would be confirmed that what got diluted out is the antigen. Detection of HIV antibodies in plasma dilutions that test DPHA negative means that titer got by the DPHA test is titer of the antigen in the sample [4].

It is possible for DPHA to test negative in plasma of a HIV-positive person because it is dependent on presence of antibodies which may not be present in blood in early cases ("window period"). So, to use it for primary confirmation of diagnosis of HIV/AIDS, periodic repeats of the test are recommended in patients that show consistent low CD4-T lymphocytes counts. For rapid confirmation of diagnosis, specimens that test negative by DPHA should be retested immediately with HIV specific serum used to replace phosphate buffered saline for serial dilution of the specimen. This will ensure that dilutions of the plasma contain high concentration of HIV antibodies that would remain constant while concentration of the antigen would reduce with each dilution, until it is diluted out.

HIV positive samples in which the viral particles are all intracellular can also test negative for the virus by DPHA test even in the presence of antibodies to the virus [6]. Incubating such samples with Aluminum-magnesium silicate (AMS) releases the cell-bound viral particles and makes the specimens test positive for HIV. So, before samples from patients who have already tested HIV/AIDS positive by the serological tests can be declared negative for the virus by DPHA test, the samples should be incubated with AMS and be diluted in HIV specific serum for the test. If a sample tests negative by DPHA test when diluted in phosphate buffered saline and still tests negative when incubated with AMS and diluted in HIV specific serum, the patient is no longer positive for HIV infection.

HIV/AIDS was first recognized as a disease of man in 1981. However, history of the disease shows it may 
have been in existence much earlier than 1981. A plasma sample taken in 1959 from an adult male from the Democratic Republic of Congo has been found to contain HIV. The virus has also been detected from tissue samples from an African-American teenager who died in St. Louis in 1969 and in tissue samples from a Norwegian sailor who died around 1976. It is believed that HIV may have been introduced into the human population as early as 1940s or in the early 1950s [1].

A number of factors may have led to world wide spread of HIV. International travel is a major factor. The first person diagnosed of HIV/AIDS in the United States of America was a Canadian flight attendant. He traveled extensively, and analysis of several other early cases showed that they had either direct or indirect sexual contact with that flight attendant. The early cases were also traced to several different American cities where these infected individuals lived, demonstrating a critical role for air travel in spreading the virus. HIV was isolated from cells of those AIDS patients. Clinical and pathological studies showed that the virus destroyed lymphocytes in the patients and could be transmitted outside their cells [1].

HIV/AIDS pandemic has become a very big health challenge in many countries of Africa. At the end of 2006, an estimated 39.5 million people in the world were said to be living with HIV, with Sub-Saharan Africa having the highest burden. The infection rate is increasing every year. An estimated 4.3 million new cases were reported in that 2006. More than 95\% of the new infections were from Asia, South America and Africa [6].

Pathogenesis of HIV infection comprises of an acute (primary) phase that lasts for few months, followed by a clinically latent phase that lasts for few years before the collapse of immune responses, leading to clinical AIDS. Even during the "window period" when HIV antibodies are not yet detectable in blood of infected persons there is still surge of viraemia and plasma load of the virus reaches peak within 2 - 3 weeks of the infection. There is also corresponding loss of lymphocytes during this period, thus causing drop in circulating CD4-T lymphocytes. The host then generates immune response that leads to decline in vireamia. This stage of acute HIV infection is usually self limiting, but about 4 - 6 months post-infection, steady state of viraemia is achieved. The plasma viral load remains stable for several years following attainment of the plasma viral load set point. The infected person remains fairly asymptomatic during this period. Although plasma virus load levels do not rise during the period, there is still multiplication of virus, leading to further destruction of the CD4-T lymphocytes [1].

Affectation of other animal species by lentiviruses gives opportunity for animal researches to develop treatment and control for HIV/AIDS in man. For instance, studies with mice and monkeys led to invention of first antiretroviral medicine in 1986. By 1996, a combination therapy, consisting of cocktails of antivirals, taken together was invented. This has increased life expectancy of HIV positive persons. Many HIV positive individuals now take just two or three pills a day to stop the infection from progressing to clinical AIDS. Animal researches also played a key role in the development of post-exposure prevention that has saved many victims of needlestick injuries and other exposures to HIV. Tests for blood before transfusion and for diagnosis of HIV infection have also been developed through animal researches [1].

Most nonhuman primates infected with SIV do not develop clinical signs, unlike human-beings infected with HIV. HIV infection is characterized by progressive loss of CD4-T lymphocytes, chronic immune activation and clinical signs of secondary infections [1]. This difference in outcome of SIV infection in the nonhuman primates and outcome of HIV infection in human-beings limits researches with the animals, for development of vaccines and for more effective treatment for HIV/AIDS.

However, Infectious bursa disease virus of chicks, shares pathogenesis with HIV [3]. This similarity in pathogenesis of IBDV and HIV makes IBDV research of interest in the effort to develop vaccines for HIV/AIDS. Destruction of lymphocytes by HIV is what makes development of vaccines for HIV/AIDS difficult. It is also known that what leads to most cases described as vaccination failures in IBDV vaccination of chickens is that the virus destroys lymphocytes in the avian bursa. Therefore, researches on IBDV in chicks could meet the demand by some public health concerns that extensive researches be conducted on animals before clinical trials of HIV vaccines on human-beings.

Studies on IBDV vaccination have shown that age of chicks at time of vaccination, type of vaccine (live or inactivated), level of maternal antibodies in the hosts at time of vaccination and virulence of virus strains in locality of the hosts affect effectiveness of vaccination. Both live and inactivated IBDV vaccines are used to vaccinate chickens and there are reports that the inactivated vaccines induce higher antibody responses than the live vaccines and that immunity from the inactivated vaccines lasts longer.

A comparative sero-evaluation of live and inactivated IBDV vaccines showed that antibody titer of chicks vaccinated with inactivated vaccines was 3582.10 while that of the group vaccinated with live vaccines was only 
1513.00. It was also observed that protection of chicks with the live vaccines lasted for a shorter period than protection with the inactivated vaccines. Vaccinating chicks with live IBD vaccines after initial vaccination with the inactivated vaccines produced higher immune responses than use of either live vaccine alone or use of inactivated vaccine alone. In spite of the many vaccination efforts made to control IBD in chicks, outbreaks of the disease keep occurring, even among vaccinated flocks.

Investigating the cause of low immunogenicity of live IBDV vaccines and causes of IBD vaccination failures was difficult because, most laboratory tests used for detection of the virus are qualitative tests. The few that are quantitative are either too expensive or too time-consuming to be used for routine diagnosis or for testing large numbers of samples, as is required in such research investigations. There was therefore need for a simple and rapid diagnostic test that can assess both IBDV titers and titers of antibodies to the virus. Successful modification of the PHA test to get the MPHA test now being used to assess titers of IBDV paved way for studies on titers of IBDV vaccines and titers of antibodies in chicks they are used to vaccinate [7].

Vaccines are administered to induce production of high levels of cellular and/or humoral immunity in vaccinated individuals. For IBDV, many vaccination schedules and a variety of vaccine strains have been used in efforts to achieve this aim, but despite these efforts, many outbreaks of the disease are still being reported, worldwide. When antibody response to a highly virulent IBD vaccine was compared with those of intermediate IBD vaccines, the "hot 512 vaccine" produced less antibody responses than the intermediate vaccines.

Target cells of IBDV infection are the B-lymphocytes. Bursa of fabricious which is responsible for immune responses in avian species comprises of $85 \%$ - 95\% B-cells. These B-cells produce the IgM which forms antibodies against infections. So, depletion of B-cells by the IBDV is a major cause of immune-suppression in pathogenesis of the infection. Live vaccines are still the virus. So, they also deplete the B-cells while the inactivated vaccines cannot deplete cells. Also, highly virulent vaccines (the hot vaccines) deplete more B-cells than the milder intermediate vaccines. Another attribute of the IBDV which determines number of bursa cells depleted, is their titer. So, vaccines that are too high in titer of live IBDV could deplete significant number of B-lymphocytes in bursa of vaccinated chicks. This may explain our observation that when IBDV titers of the vaccines were plotted on a graph against IBDV antibody titers in chicks they were used to vaccinate, there was an inverse relationship between the vaccine titers and antibody titers in the chicks [8].

A study of IBD in India has also revealed that out of 483 outbreaks, 334 (69\%) were among vaccinated flocks while unvaccinated flocks had only 149 outbreaks (31\%). The difference between $69 \%$ and $31 \%$ is statistically significant. The study, therefore, suggests that IBDV vaccination was found to be a predisposing factor for IBD outbreaks in India, instead of being the control measure it was intended to be.

These reports and our observations, suggest that most outbreaks of IBD, in vaccinated flocks, thought to be vaccination failures are cases of acquired immunodeficiency syndrome, caused by the live vaccines. So, for IBD in chickens, use of inactivated vaccines could be adopted since it is a disease of chicks aged between 3 weeks and 6 weeks. Beyond this age range, chances of IBD in chickens even when experimentally challenged with the virus are low. So, immunity from IBDV vaccination does not need to last for a long time. On the other hand, HIV/AIDS can occur at any age. So, vaccine for the infection should be able to produce immunity that would last for a long time.

Use of inactivated vaccines or subunit vaccines for HIV/AIDS may not be convenient because immunity from such vaccines would last for so short a period that people would need to be revaccinated within very short intervals as is the practice in IBDV vaccination of chicks. Live HIV vaccine should also not be suggested because even if it is attenuated enough to ensure it does not cause vaccine-induced HIV/AIDS in the primary recipients, transmitting the attenuated viruses (vaccines) from vaccinated persons to other persons, by sexual contacts and by blood transfusion, could reactivate the vaccines to virulent HIV. It is therefore suggested that current methods of controlling HIV/AIDS by safe sex practices, public education and screening of blood before transfusion be stepped up while research attention should be to develop more effective and affordable treatment for the syndrome.

Development of antiviral medicines is difficult, because most substances which have antiviral effects are harmful to normal cells [9] [10]. Also, viruses easily change their biochemical compositions and so, are able to develop resistance against available antiviral medicines. For safer antiviral medicines and to reduce rate of development of resistance against the medicines, it has been suggested that antiviral medicines that act by physical effects be developed, instead of those that have biochemical effects.

Aluminum-magnesium silicate (AMS) is not harmful to normal cells [11]. Each molecule of the AMS is 
composed of platelets that are only $0.96 \mathrm{~nm}$-thick. So it is made of Nanoparticles [12]. Surfaces of the AMSNanoparticles have negative electrical charges while their edges have positive electrical charges [11]. Genome of every virus is made of positively charged ions, such as, $\mathrm{Na}^{+}, \mathrm{Mg}^{++}$and $\mathrm{K}^{+}$while the phosphate component is negatively charged [13]. So, every virus has either a net negative electrical charge or a net positive electrical charge. DNA viruses have net negative electrical charges while RNA viruses are positively charged [14]. Presence of opposite electrical charges on AMS-Nanoparticles and on viruses make viral particles to adsorb onto the Nanoparticles, thus blocking viral adsorption onto cells which is first stage in viral infection of cells.

In patients, AMS-Nanoparticles adsorb onto viral particles released from infected cells. So, new foci of the infections are minimized. Reduction of number of foci of infections gives body immune systems advantage over viral infections so that synergy between the patients' immune responses and antiviral effects of the AMS-Nanoparticles leads to recovery from the viral infections [6].

Among challenges encountered in managing viral diseases is failure of most antimicrobials to reduce secondary infections to levels that make it impossible for pathogens, such as bacteria, protozoa and helminthes to develop resistance against medicines used for treatment of their infections. To ensure disease agents do not develop resistance against medicines, treatment with the medicines should reduce loads of the infections by at least 95\%. Adjuvants are therefore often needed in formulations of antimicrobials, to potentiate them to achieve the required level of clearance of infections [15].

The two opposite electrical charges on the AMS-Nanoparticles make them, when in solution, to hydrate to form three dimensional colloidal structures [1]. The structures stabilize medicines that are in formulations with AMS. To stabilize means to protect against destruction. So, the Nanoparticles protect medicines from being rapidly degraded by metabolic processes so that bioavailability of the medicines is prolonged. When bioavailability is prolonged, effects of antimicrobials improve [16]. Improved effects of antimicrobials against secondary infections would also help in managing HIV/AIDS cases.

Nigeria does not have deposits of natural AMS but two other minerals also used in oral medications; Aluminum silicate and Magnesium silicate are abundant in the country. These two medicinal minerals were reacted to get a synthetic form of AMS $\left\{\mathrm{Al}_{4}\left(\mathrm{SiO}_{4}\right)_{3}+3 \mathrm{Mg}_{2} \mathrm{SiO}_{4} \rightarrow 2 \mathrm{Al}_{2} \mathrm{Mg}_{3}\left(\mathrm{SiO}_{4}\right)_{3}\right\}$. Dextrose monohydrate, a simple sugar was added to the medicinal synthetic AMS, to carry its molecules, by active transport, across mucous membranes of stomachs and intestines of treated patients, into blood circulation [10].

In vitro studies have demonstrated that the medicinal synthetic AMS inhibits viruses of all the six viral families so far tested (Paramyxoviridae, Orthomyxoviridae, Birnarviridae, Parvorviridae, Avipoxviridae and Retroviridae) which comprised of six RNA viruses and three DNA viruses. It cured animals experimentally challenged with viruses of Paramyxoviridae, Birnarviridae and Parvoviridae families which also included both RNA and DNA viruses [17]-[23].

Making formulations of Sulphadimidine, Chloroquine, Ampicillin and Piparazine in the medicinal synthetic AMS potentiated the antimicrobials to reduce infection rates of coccidia, plasmodium, salmonella and helminthes, respectively, by as much as $95 \%$ or more in experimentally challenged animals. Ampicillin stabilized with it and used in synergy with immune stimulants, regained antibacterial effects against an Ampicillin-resistant E. coli infection [24]-[29].

In the in vitro experiment to assess effects of the Medicinal synthetic AMS on HIV, mean titers of the virus in plasma incubated with it increased significantly $(\mathrm{P}=0.009)$ from $4.00 \pm 1.60$ to $14.00 \pm 2.00$ which suggests that it destroys HIV-infected cells to release particles of the virus that are intracellular. A repeat incubation of supernatants of the plasma samples with the medicinal synthetic AMS reduced mean HIV titers in the plasma, significantly $(\mathrm{P}=0.024)$, from $14.00 \pm 2.00$ to $6.50 \pm 1.50$. That demonstrates that it also adsorbs out extracellular HIV particles.

Patients who have so far completed treatment with the medicinal synthetic AMS reported that it also had antiretroviral effects, in vivo. All seven patients who have completed three months daily medication with the medicine claimed that the clinical signs ceased following the treatment. One of the patients reported that copies of RNA in his plasma reduced from $1000 / \mathrm{ml}$ to $70 / \mathrm{ml}$ after treatment for one month while the one who treated himself with the medicine for two months before testing for viral load reported that copies of RNA in his plasma reduced from $1000 / \mathrm{ml}$ to $40 / \mathrm{ml}$. A patient who has been on the treatment for over five months while waiting to have the viral load test, reported that she does not experience any adverse drug reaction. Presence of less than 50 copies of RNA/ml of plasma of a patient who was HIV positive suggests that the medicinal synthetic AMS cured the infection. 
Ebola virus disease (EVD) is another disease caused by an RNA virus which like HIV/AIDS, is of current global importance. Since, the medicinal synthetic AMS, acts by physically adsorbing onto whichever opposite electrical charge a virus has, it may also be effective against EVD [30].

\section{References}

[1] HIV/AIDS: Where Did HIV Come from?

http://www.infoplease.com/cig/dangerous-diseases-epidemics/hiv-origins.html\#ixzz3OcwXMs00

[2] Yokoyama, M. (2011) Structural Mechanisms of Immune Evasion of HIV 1 gp 120 by Genomic Computational and Experimental Science. Uirusu, 61, 49-57. http://dx.doi.org/10.2222/jsv.61.49

[3] Benton, W.J., Cover, M.S. and Rosenberg, J.K. (1967) Studies on the Transmission of the Infectious Bursa Agent (IBA) of Chickens. Avian Diseases, 11, 430-438. http://dx.doi.org/10.2307/1588191

[4] Ezeibe, M.C.O., Ngene, A.A., Anene, I., Amechi, B., Olowoniyi, P., Eze, J.I. and Animoke, P.C. (2013) Direct Passive Hemagglutination Test for Rapid Quantification of Plasma Loads of the Human Immunodeficiency Virus. Health, 5, 1351-1354. http://dx.doi.org/10.4236/health.2013.59183

[5] Ezeibe, M.C.O., Okoye, J.O.A., Ogunniran, T.M., Okoroafor, O.N., Ezeala, I.E. and Ngene, A.A. (2012) Modification of the Passive Heamagglutination Test for Detection of Infectious Bursal Disease Virus. Health, 4, 653-655. http://dx.doi.org/10.4236/health.2012.49102

[6] Ezeibe, M.C.O., Ngene, A.A., Kalu, I.K., Ezeh, I.O., Mbuko, I.J., Ekwuruke, J.O., Anene, I., Amechi, B., Olowoniyi, P. and Ifekwe, I.F. (2014) Assessment of Antiretroviral Effects of a Synthetic Aluminum-Magnesium Silicate. BJMMR, 4, 1676-1679.

[7] Ezeibe, M.C.O., Okoye, J.O.A., Ogunniran, T.M., Animoke, P.C., Mbuko, I.J., Nwankwo, I.A. and Ngene, A.A. (2013) Mortality Rates from a Nigerian Isolate of the Infectious Bursa Disease Virus and Passive Haemagglutination Antibody Titer That Protects Chicks against Challenge with the Virus. Health, 5, 1355-1359. http://dx.doi.org/10.4236/health.2013.59184

[8] Ezeibe, M.C.O., Okoye, J.O.A., Ogunniran, T.M., Animoke, P.C., Ijeoma, J., Mbuko, I.J., Nwankwo, I.A. and Ngene, A.A. (2014) Effects of Live Infectious Bursa Disease Vaccines, on Immune Response of Vaccinated Chicks. BJMMR, 4, 1506-1513. http://dx.doi.org/10.9734/BJMMR/2014/6205

[9] Ezeibe, M. (2009) The Synthetic Aluminum-Magnesium Silicate. Great AP Express Pub. Ltd., Nsukka.

[10] Ezeibe, M.C.O. (2014) The Synthetic Aluminum-Magnesium Silicate (Nanoparticles). Federal Republic of Nigeria Patents and Designs Act. Cap 344 LFN 1990, NO. NG/P/639.

[11] Vanderbilt Report (2012) Technical Information: "VEEGUM-The Versatile Ingredient for Pharmaceutical Formulations. R.T. Vanderbilt Company Bulletin No. 91R, 1984. R.T. Vanderbilt Company, Inc., Norwalk. www.rtvanderbilt.com

[12] Cristina, E., Ivan, P. and Kevin, R. (2007) Nanomaterials and Nanoparticles: Sources and Toxicity. Biointerphases, 2, MR17-MR71.

[13] Brooks, G.F. (1998) Medical Microbiology. 21st Edition, McGraw Hill Education Inc., San Francisco.

[14] Cann, A.J. (1993) Principles of Molecular Biology. Academic Press, San Diego.

[15] Kaplan, R.M. (2002) Anthelmintic Resistance in Nematods of Horses. Veterinary Research, 12, 491-507. http://dx.doi.org/10.1051/vetres:2002035

[16] Brent, W., Gunderson, Gigi, H., Ross, K.H.I. and John, C.R. (2001) What Do We Really Know about Antibiotics Pharmacodynamics? Pharmacotherapy, 21, 28-31.

[17] Ezeibe, M.C.O., Mbuko, I.J., Okoroafor, O.N., Okonkwo, A.C., Animoke, P.C., Orajaka, L.J.E. and Ngene, A.A. (2009) In Vitro and in Vivo Effects of Aluminium-Magnesium Silicate on Infectious Bursal Disease Virus in Chickens. Animal Science Reporter, 3, 132-137.

[18] Ezeibe, M.C.O., Ijabo, O., Okoroafor, O.N., Orajaka, L.J.E., Ukomadu, N.M. Chukwu, O.S. and Ngene, A.A. (2009) Antiviral Effects of Aluminum-Magnesium Silicate on Peste des Petits Ruminants Virus. Animal Science Reporter, 3, 141-147.

[19] Ezeibe, M.C.O., Okoroafor, O.N., Ijabo, O., Ukomadu, N.M., Ngene, A.A. and Eze, J.I. (2010) Haemagglutination and Haemagglutination Inhibition Titres of Egg Drop Syndrome 76 Virus Treated with Aluminium Magnesium Silicate. Animal Science Reporter, 4, 87-90.

[20] Ezeibe, M.C.O., Nwaogu, I.C., Nwaigwe, A.N., Okoroafor, O.N., Eze, J.I. and Ngene, A.A. (2010) AluminiumMagnesium Silicate Inhibits Canine parvovirus and Cures Infected Dogs. Health, 2, 1215-1217.

http://dx.doi.org/10.4236/health.2010.210179 
[21] Ezeibe, M.C.O., Ijabo, O., Uzopuo, C., Okoroafor, O.N., Eze, J.I., Mbuko, I.J., Sanda, M.E., Animoke, P.C. and Ngene, A.A. (2011) Effects of Aluminium-Magnesium Silicate on Newcastle Disease Virus and on Recovery of Infected Chicks. International Journal of Biological and Chemical Sciences, 5, 825-829. http://dx.doi.org/10.4314/ijbcs.v5i2.72160

[22] Ezeibe, M.C.O., Egbuji, A.N., Eze, J.I., Ijabo, O., Ngene, A.A., Okoroafor, O.N., Eze, I.C., Ugonabo, J.A.C., Sanda, M.E. and Mbuko, I.J. (2012) Antiviral Effects of a Synthetic Aluminium-Magnesium Silicate on Avian Influenza Virus. Health, 4, 429-432. http://dx.doi.org/10.4236/health.2012.47067

[23] Ezeibe, M.C.O., Ekeanyanwu, E., Ngene, A.A. and Mbuko, I.J. (2013) Aluminum-Magnesium Silicate Enhances Release of Virions of Cultured Fowlpox Virus and Inhibits the Virus. Health, 5, 1394-1396. http://dx.doi.org/10.4236/health.2013.59190

[24] Ezeibe, M.C.O., Okafor, U.C., Okoroafor, O.N., Eze, J.I., Ngene, A.A., Animoke, P.C. and Mbuko, I.J. (2011) Effect of Aluminium-Magnesium Silicate on Anticcocidial Activity of Sulphadimidine. Tropical Veterinarian, 29, 41-44.

[25] Ezeibe, M.C.O., Elendu-Eleke, N.P., Okoroafor, O.N. and Ngene, A.A. (2012) Adjuvant Effect of a Synthetic Aluminium-Magnesium Silicate on Chloroquine Phosphate, against Plasmodium berghei. Health, 4, 448-451.

[26] Ezeibe, M.C.O., Anosa, G.N., Okorie, O.K., Elendu-Eleke, N.P., Okoroafor, O.N, Ngene, A.A. and Chikelu, O.N. (2012) Aluminum-Magnesium Silicate Enhances Antibacterial Activity of Ampicilline Trihydrate, against S. gallinarum. Nature Proceedings. http://hdl.handle.net/10101/npre.2012.6814.1

[27] Ezeibe, M.C.O., Dire, C.D., Anosa, G.N., Chikelu, O.N., Okoroafor, O.N., Okorie, O.K., Ngene, A.A., Idika, I.K., Ogunniran, T.M. and Ezeala, I.E. (2012) Efficacy of Piperazine Citrate, Stabilized with Aluminum-Magnesium Silicate, against Helignosomoides bakeri. Health, 4, 890-892. http://dx.doi.org/10.4236/health.2012.410135

[28] Ezeibe, M.C.O., Chima, U.M., Ngene, A.A., Okoroafor, O.N., Kalu, I.I. and Esen, M.E. (2012) Effective Treatment of Resistant Escherichia coli Infection, with Sulphadimidine Stabilized in a Synthetic Aluminum-Magnesium Silicate. Health, 4, 1295-1298. http://dx.doi.org/10.4236/health.2012.412190

[29] Ezeibe, M.C.O., Ezeobele, O.K., Esen, M.E., Ngene, A.A., Mbuko, I.J., Chukwudi, I.C., Omoja, V.U. and Ezeh, I.O. (2013) Synergy in Antibacterial Activities of Ampicillin Trihydrate, Stabilized with a Synthetic Aluminum-Magnesium Silicate and Immune-Stimulants, on Resistant Escherichia coli Infection. Health, 5, 1548-1552. http://dx.doi.org/10.4236/health.2013.510210

[30] Ezeibe, M.C.O. (2014) Antiretroviral Effects of a Medicinal Synthetic Aluminum-Magnesium Silicate. Proceedings of 1st Nigerian Research Education Network Lecture Series. 